DOI: https://doi.org/10.35699/2238-037X.2020.19618

\title{
AS CONCEPÇÕES DE EDUCAÇÃO INTEGRAL E INTEGRADA EM JOHN DEWEY
}

\author{
The conceptions of integral and integrated education in John Dewey
}

FREITAS, Cezar Ricardo de1 FIGUEIREDO, Ireni Marilene Zago²

\begin{abstract}
REsumo
Este estudo tem como objetivo discutir os conceitos de Educação Integral e Educação Integrada em três obras de John Dewey (1859-1952): "Liberalismo, Liberdade e Cultura"; "Democracia e Educação" e "Experiência e Educação", todas da década de 1930. Para apreender os conceitos de Educação Integral e Integrada, considerou-se a relação com os seguintes conceitos deweyanos: educação e democracia; educação e contradições sociais; educação moral e formação de hábitos morais e intelectuais; ensino e experiência; educação e liberdade individual; educação e trabalho, entre outros necessários à contextualização da discussão. A Educação Integrada e Integral em Dewey são indissociáveis, porém, pode-se concluir que a Educação Integrada seria aquela que resolvesse os problemas da sociedade, apontados por Dewey, como a exclusão social e a ausência de valores democráticos. Para que a escola desenvolvesse essa dimensão integrada à sociedade, o filósofo norteamericano desenvolveu, concomitantemente, uma concepção de Educação Integral: uma estratégia educacional pautada no desenvolvimento da liberdade do aluno, e que pressupõe o desenvolvimento do aspecto intelectual e do corpo, preocupada, inclusive, com a dimensão do trabalho. Embora com perspectiva diferente, há no filósofo uma preocupação de dialogar com temáticas propostas por socialistas, como a crise do capitalismo da década de 1930, os problemas gerados pela exclusão social, e a necessidade de vinculação entre educação e trabalho.
\end{abstract}

Palavras-chave: John Dewey. Educação Integral. Educação Integrada. Liberalismo.

\section{Abstract}

This study aims to discuss the concepts of Integral Education and Integrated Education in three works by John Dewey (1859-1952): "Liberalism, Freedom and Culture"; "Democracy and Education" and "Experience and Education", all from the 1930s. To understand the concepts of Integral and Integrated Education, the relationship with the following deweyan concepts was considered: education and democracy; education and social contradictions; moral education and formation of moral and intellectual habits; teaching and experience; education and individual freedom; education and work, among others necessaryfor the contextualization of the discussion. Integrated and Integral Education in Dewey are inseparable, however, it can be concluded that Integrated Education would be the one that solved the problems of society pointed out by Dewey, such as social exclusion and the absence of democratic values. In order for the school to develop this dimension integrated into society, the American philosopher concomitantly develops a conception of Integral Education: an educational strategy based on the development of student freedom, and which presupposes the development of the intellectual aspect and the body, concerned including the dimension of the work. Although with a different perspective, there is

\footnotetext{
${ }^{1}$ Doutorando em Educação pela Universidade Estadual de Maringá - UEM. Mestre em Educação pelo Programa de Pós-Graduação em Educação da UNIOESTE - Universidade Estadual do Oeste do Paraná - Campus de Cascavel - PR. Professor da Universidade Tecnológica Federal do Paraná - UTFPR - Campus Toledo - PR. Pesquisador do Grupo de Pesquisa em Educação e Educação Matemática da UTFPR. E-mail: cezarfreitas@uttpr.edu.br

2 Doutora em Educação pela Universidade Estadual de Campinas - UNICAMP/SP. Professora do Colegiado do Curso de Pedagogia e do Mestrado em Educação da UNIOESTE - Universidade Estadual do Oeste do Paraná - Campus de Cascavel - PR. Pesquisadora do Grupo de Estudos e Pesquisas em Política Educacional e Social - GEPPES. E-mail: irenifigueiredo@hotmail.com
} 
in the philosopher a concern to dialogue with themes proposed by socialists, such as the crisis of capitalism in the 1930s, the problems generated by social exclusion, and the need to link education and work.

Keywords: John Dewey. Integral Education. Integrated Education. Liberalism.

\section{DE ONDE PARTIMOS?}

Este artigo é parte de uma pesquisa ${ }^{3}$ que analisou a concepção de Educação Integral e Integrada em John Dewey (1859-1952) e nos teóricos socialistas da Rússia das três primeiras décadas do século XX. A hipótese inicial de pesquisa era a de que 0 Escolanovismo havia se apropriado do conceito de Educação Integral Socialista transplantando-os para a Sociedade Capitalista e, com isso, descaracterizando-o, assumindo a perspectiva de uma Educação Integrada.

Considerando essa hipótese, o entendimento era de que uma proposta de Educação Integral somente seria possível no Socialismo e o Escolanovismo, no limite, somente poderia efetivar uma proposta de Educação Integrada. Esse pressuposto não se sustentou com a continuidade das investigações, uma vez que se identificou uma apropriação recíproca, mas que, no entanto, existiam elementos que as diferenciavam, o que exigiu a compreensão do contexto histórico em que tais perspectivas foram formuladas.

Foi assim que a investigação sobre a origem dos conceitos de Educação Integral e Integrada reforçou a insustentabilidade da hipótese inicial, na medida em que foi possível identificar os dois conceitos nas propostas de educação em John Dewey e nos teóricos da Rússia Soviética. Esse entendimento foi sendo construído na compreensão de que os conceitos não são universais e que assumem diferentes sentidos ou significações, bem como respondem a determinadas necessidades, respeitando as particularidades de cada tempo e lugar (PEIXOTO, 1998); entendendo-os, dessa forma, como produto das relações complexas e imbricadas das dimensões econômico-social e políticoideológica de um determinado contexto histórico. Chama a atenção o fato de que é a educação, como atividade externa ao indivíduo, que tem a tarefa de recompor ou desenvolver a essência humana, que por motivos históricos e sociais, apresenta-se dividida ou parcialmente desenvolvida. Os motivos dessa divisão, bem como o entendimento de qual a perspectiva de "integral", variam de acordo com os autores e os contextos analisados.

Diante dessas questões, neste artigo o recorte é o de analisar as concepções de Educação Integral e Integrada em John Dewey que, sem dúvida, é um dos principais teóricos da educação do século XX e sua obra continua produzindo impactos ainda no século XXI. Principal referência do chamado movimento da Escola Nova, ou Educação Progressiva, "[...] a grande criação de Dewey, nascida das entranhas de seu desejo de pensar a educação norte-americana em particular e/ou a educação liberal de modo geral" (JONES, 1989, p. 118), teve representantes em vários países. No caso brasileiro, Dewey foi assumido pelos educadores liberais e por nossos preceitos legais em

\footnotetext{
${ }^{3}$ Este trabalho é resultado de pesquisa de mestrado em Educação, intitulado "O Escolanovismo e a Pedagogia Socialista na União Soviética no início do século XXe as concepções de Educação Integral e Integrada (FREITAS, 2009). A pesquisa teve apoio da Capes por meio do Programa de Demanda Social.
} 
educação4, mas "[...] cuja concretização, ao menos na esfera da formação escolar das classes trabalhadoras, se tornou mera especulação" (JONES, 1989, p. 116).

Reafirma-se, então, que se os conceitos não são universais, numa breve análise histórica nos permite compreender que a ênfase dada à formação integral do homem está na origem do conceito grego de Paidéia, de difícil definição, e que expressou o ideal de formação dos gregos a partir do século $V$ a.C. e influenciou o que os romanos chamaram de humanistas; sendo retomado, no século XVIII, pelos lluministas.

Neste sentido, a preocupação com uma Educação Integral tem origem nas chamadas "civilizações clássicas", Grécia e Roma, ambas escravistas, onde alguns filósofos defendiam uma formação que desenvolvesse o processo de construção pessoal consciente, permitindo ao indivíduo ser "constituído de modo correto e sem falha, nas mãos, nos pés e no espírito". A Educação Grega, reservada somente para a Aristocracia, centrava-se na formação integral, "corpo e espírito", com ênfase para o preparo militar ou esportivo ou para o debate intelectual, conforme a época ou o lugar (ARANHA, 2006, p. 61-63).

Aristóteles (384-322 a.C.), por exemplo, reconhecia a importância de uma Educação Integral, que exigiria o cultivo de todas as disposições humanas. Sobre a educação afirmava que "Cosas que deben ser objeto de ella: las letras, lagimnástica, la música y el dibujo" (ARISTÓTELES, 2008, p. 06). Afirmava, nesse sentido, que a educação não deveria voltar-se somente para o necessário, mas também para o belo: "Se debe, pues, reconocer que hay ciertas cosas que es preciso enseñar a los jóvenes, no como cosas útiles o necesarias, sino como cosas dignas de ocupar a um hombre libre, como cosas que son bellas." (ARISTÓTELES, 2008, p. 74). Destaque para a preocupação do filósofo com a educação do homem livre ou cidadão, aquele que participa da política do Estado, excluindo escravos, estrangeiros e mulheres. Os conhecimentos úteis e necessários para tornar-se cidadão, excluem, por exemplo, a dimensão do trabalho, manual ou artesanal, que poderiam prejudicar o desenvolvimento integral do sujeito:

[...] la juventud sólo aprenderá, entre las cosas útiles, aquellas que no tiendan a convertir en artesanos a los que las practiquen. Se llaman ocupaciones propias de artesanos todas aquellas, pertenezcan al arte o a la ciencia, que son completamente inútiles para preparar el cuerpo, el alma o el espíritu de un hombre libre para los actos y la práctica de la virtud. También se da el mismo nombre a todos los oficios que pueden desfigurar el cuerpo y a todos los trabajos cuya recompensa consiste en un salario, porque unos y otros quitan al pensamiento toda actividad y toda elevación (ARISTÓTELES, 2008, p. 73).

Considerando a particularidade acima, a Educação Integral, em Aristóteles, achava-se em íntima relação com um desenvolvimento progressivo: as funções físicas, vegetativas, instintivas e racionais do homem desenvolvem-se passo a passo, de modo pausado. Seria preciso desenvolver as disposições corporais e instintivas antes de ocupar-se intensamente da razão e do caráter. A educação, em outras palavras, deveria aperfeiçoar a natureza humana, de maneira gradual (LARROYO, 1982, p. 183-184).

\footnotetext{
${ }^{4}$ Souza e Martineli (2009) apontam dois períodos de influência do pensamento deweyano no Brasill: de 1930 a 1950; e depois em 1990. Os dois períodos são marcados por reformas importantes na educação, mas é o primeiro período que teve maior impacto. Neste, destacase o pensamento pedagógico de Anísio Teixeira (1900-1971), "O primeiro e mais destacado autor a mencionar John Dewey nos periódicos brasileiros" (CUNHA, 2001, p. 89). Teixeira, que foi aluno de John Dewey nos EUA, e teve um protagonismo nas reformas educacionais da década de 1930. Ao analisar as matrizes do pensamento de Teixeira, Sabina Silva (2010) afima que "Anísio Teixeira assume integralmente o corpus intelectual de Dewey" (SILVA, 2010, p. 195).
}

Trabalho \& Educação | v.29 | n.2 | p.197-215 | maio-ago. | 2020 
Em relação à Educação Integrada, analisamos no sentido de vinculação entre escola e sociedade, e entre educação e trabalho, preocupações mais recorrentes a partir da sociedade industrial e com destaque na perspectiva socialista, com a qual Dewey vai "dialogar". Em Dewey, buscaremos elementos que apontem preocupações de uma educação que se integre a sociedade, no sentido de contribuir para enfrentar os dilemas e contradições da sociedade.

Convém ressaltar, também, que

[...] historicamente os ideais e as práticas educacionais reformadoras, reunidos sob a denominação de Escola Nova, fizeram uso, com variados sentidos, da noção de educação integral. [...] O movimento reformador, do início do século XX, refletia a necessidade de se reencontrar a vocação da escola na sociedade urbana de massas, industrializada e democrática (CAVALIERE, 2002, p. 251. Grifos da autora).

Portanto, para além das várias vertentes do movimento escolanovista, analisamos as propostas de Educação Integral e Integrada em John Dewey, considerado o maior expoente do escolanovismo, que influencia ainda hoje, o cenário educacional. A relevância desta discussão parte da constatação de que essas concepções frequentemente aparecem no discurso educacional, como inovadoras ou revolucionárias, sem explicitar quais os seus fundamentos, suas bases históricas e epistemológicas, impedindo uma reflexão crítica e uma apropriação para além do "consumo" de conceitos prontos. É o caso, por exemplo, da conotação salvacionista que aparece frequentemente vinculado à discussão sobre a Educação Integral. Este estudo, portanto, busca contribuir para a análise da Educação Integral, ao identificar os pressupostos de um de seus principais formuladores, John Dewey. Ao apontar elementos do diálogo desse autor com as preocupações socialistas, o estudo também ajuda a situar as diferenças de perspectiva sobre a temática.

A pesquisa foi de cunho bibliográfico, com enfoque em três obras de Dewey da década de 1930, época em que o seu pensamento se propagou pelo Brasil, consequência, em boa parte, do movimento escolanovista. A seleção das obras expressa ao mesmo tempo, a relevância da publicação e a presença da problemática investigada. A obra "Democracia e Educação" (DEWEY, 1979a) escrita, originalmente, em 1916, foi traduzida por Anísio Teixeira, no Brasil, em 1936. Essa obra, segundo Dewey, é um esforço para penetrar e definir as ideias implícitas em uma sociedade democrática e para aplicá-las aos problemas da educação (DEWEY, 1979a, p. XXVII. Prefácio da 1aㅡ edição). A segunda obra "Liberalismo, Liberdade e Cultura" foi publicada no Brasil, em 1970, e contempla as obras "Liberalismo e Ação Social", de 1935, e "Liberdade e Cultura", de 1939. "Experiência e Educação" (DEWEY, 1979b), escrita em 1938, é a terceira obra. Nesta última, Dewey apresenta as críticas à escola tradicional, ao mesmo tempo em que descreve e ilustra um de seus conceitos educacionais fundamentais: o ensino a partir da experiência (DEWEY, 1979b, p. XII). Também posiciona-se diante do movimento educacional renovador, criticando alguns de seus desdobramentos, ou "mal-entendidos" e reafirmando as suas ideias fundamentais (CUNHA, 1994, p. 86).

O percurso metodológico da investigação das obras foi a de apreender nos conceitos fundamentais do vasto pensamento de Dewey expressões ou indícios das concepções de Educação Integral e Integrada. Nesse sentido, problematiza-se, neste texto, a relação entre os seguintes conceitos: educação e democracia; educação e contradições sociais; educação moral e formação de hábitos morais e intelectuais; ensino e experiência; educação e liberdade individual; educação e trabalho. A apresentação da discussão a 
partir desses pares de conceitos indica o caminho que seguimos para apreender a perspectiva do Filósofo americano sobre a temática, ao mesmo tempo, sinalizam para o que ele analisa como obstáculos para uma Educação Integral e Integrada. Outros elementos foram necessários à contextualização da discussão, como a crítica à chamada "escola tradicional" e o debate com alguns temas da concepção socialista de educação, que também buscava uma Educação Integral e Integrada.

Diante disso, o presente texto está organizado em duas seções. Na primeira seção apresenta-se a ideia de como uma Educação Integrada está presente nas discussões sobre o papel da educação, realizada por Dewey. Na segunda seção discutem-se os elementos de Educação Integral presentes na Pedagogia desse autor. Pondera-se, todavia, que esta divisão entre Integral e Integrada é apenas didática, pois a Educação Integral, que diz respeito mais às estratégias formativas constitui-se numa das condições para resolver a perspectiva de uma Educação Integrada, que se refere à função da escola na sociedade.

\section{JOHN DEWEY E A CONCEPÇÃO DE EDUCAÇÃo INTEGRADA: UMA EDUCAÇÃO VINCULADA AOS PROBLEMAS DA SOCIEDADE}

O objetivo desta seção é apontar a ideia de uma Educação Integrada expressa nas preocupações entre a escola e a sociedade, a partir da relação entre os conceitos de educação e contradições sociais; educação e democracia; educação moral e formação de hábitos morais e intelectuais.

As elaborações de John Dewey são a expressão, no campo educacional, do Liberalismo (CUNHA, 1979, p. 49-50). Embora situado na segunda fase do liberalismo, "[...] absorvendo muito das críticas elaboradas contra o liberalismo clássico e suas extremações" (WARDE, 1984, p, 106), as suas reflexões ultrapassaram esse período, tendo impactos no período do "liberalismo multifacetado", após a Segunda Guerra Mundial. Nesta fase foi introduzido o tema "antitotalitarismo" e o liberalismo buscou diferenciar-se, tanto dos regimes fascistas, quanto dos socialistas. Para isso, pensadores norte-americanos ofereceram o suporte teórico, dentre eles, Dewey (WARDE, 1984).

O filósofo John Dewey viveu na segunda metade do século XIX e na primeira metade do século XX. O período de análise de Dewey refere-se ao contexto de crise econômicopolítica mundial do capitalismo, ao qual o liberalismo buscava responder. Deve-se mencionar, portanto, que Dewey elaborou um trabalho mais amplo, indicando a necessidade de reformulação do liberalismo que prenunciava uma crise, diante dos desafios colocados pelo desenvolvimento da própria sociedade e dos riscos iminentes em sua época, tanto do Fascismo quanto do Socialismo. A crise do liberalismo, para Dewey, é decorrente da descrença em seus princípios, na qual ocorre uma inversão da ideia progressista do liberalismo para uma concepção conjuntural e ultrapassada. A decorrência prática dessa descrença, não apenas subjetiva, já era sentida no período no qual o autor escreveu (PEIXOTO, 1998, p. 125-127).

O desenvolvimento de uma crise mundial, na década de 1930, atinge sensivelmente 0 pensamento de John Dewey. A tensão das doutrinas totalitárias da época - o Nazifascismo, o Fascismo e o Comunismo de inspiração Stalinista - coloca-o diante do desafio de uma reflexão quanto aos descaminhos do liberalismo; doutrina que sustentou suas produções (CUNHA, 1994, p. 68). A democracia e sua relação com a educação torna-se um elemento central de sua produção. Essa discussão seria a expressão de 
uma educação integrada aos problemas políticos e sociais do seu tempo. O método da democracia, para Dewey, se apoia na crença de melhoria da sociedade e de correção das suas distorções pela via da educação dos indivíduos (WARDE, 1984, p. 62). O primeiro e mais importante degrau do processo de democratização, para Dewey, seria universalizar a educação (DORES SOARES, 2000, p. 258)

Dewey reconhecia a dificuldade de a sociedade produzir espontaneamente, a democracia, isto é, tornar-se aberta. Aponta a tendência, esta sim espontânea, da educação ser utilizada como um meio de diferenciar os indivíduos, de produzir "iniquidades". Mas, apesar disso, destaca o caminho para a mudança, isto é, para a utilização da educação como instrumento de equalização (CUNHA, 1979, p. 46). Diante disso, Dewey retomava e ajudava a consolidar uma das características do "liberalismo educacional": a ideia de uma escola equalizadora da sociedade.

Significa, sim, que devemos criar nas escolas uma projeção do tipo de sociedade que desejaríamos realizar; e formando os espíritos de acordo com esse tipo, modificar gradualmente os principais e mais recalcitrantes aspectos da sociedade adulta [...] (DEWEY, 1979a, p. 349-350).

Saviani (1989) aponta que a educação enquanto fator de equalização social será, nessa perspectiva,

\begin{abstract}
um instrumento de correção da marginalidade na medida em que cumprir a função de ajustar, de adaptar os indivíduos à sociedade, incutindo neles o sentimento de aceitação dos demais e pelos demais. Portanto, a educação será um instrumento de correção da marginalidade na medida em que contribuir para a constituição de uma sociedade cujos membros, não importam as diferenças de quaisquer tipos, se aceitem mutuamente e se respeitem na sua individualidade específica (SAVIANI, 1989, p. 20).
\end{abstract}

A educação para Dewey, portanto, seria fundamental para alcançar a igualdade, reafirmando o caráter redentor da escola:

Devem assegurar-se as facilidades escolares com tal amplitude e eficácia que, de fato, e não em nome somente, se diminuam os efeitos das desigualdades econômicas e se outorgue a todos os cidadãos a igualdade de preparo para suas futuras carreiras (DEWEY, 1979a, p. 105).

Para Dewey, se o capitalismo levava à desigualdade social, a educação seria uma "via" para conduzir à igualdade. Entre todas as novidades estimuladas pelo capitalismo, a escola, para Dewey, seria a única que se manteria como possibilidade equalizadora da sociedade (DORE SOARES, 2000, p. 239). Esse atributo da escola está vinculado ao entendimento, de Dewey, de que o capitalismo no decurso de seu desenvolvimento produziu, ao mesmo tempo, riqueza e miséria. Portanto, a "dimensão concentradora e injusta do capitalismo" seria "menos um problema econômico e mais um problema moral" que se resolveria com uma "nova mentalidade humana" (BORGES, 2006, p. 54), portanto, uma tarefa educativa, de uma escola integrada a esses problemas.

Dizer que a questão é um problema moral é dizer que importa, afinal, em escolha e ação pessoal. De certo ponto de vista, tudo que dissemos resume-se ao laborioso exame de um lugar-comum: o de que o governo democrático é uma função de opinião pública e de sentimento público. Mas a identificação de sua formação no sentido e direção democráticos com a extensão da democracia da moral científica até fazê-la parte do equipamento ordinário de cada indivíduo comum, indica que o problema é um problema moral (DEWEY, 1970, p. 237). 
Essa preocupação com o problema moral expressa a sua concepção de Educação Integrada. Dewey apontava que os objetivos e os valores desejáveis na educação são todos eles morais: a disciplina, o desenvolvimento natural, a cultura e a "eficiência social". São os valores que integrariam o indivíduo à sociedade pois, de outra forma, quando não ocorre a conexão entre os métodos do conhecimento e o desenvolvimento da moral, "o conhecimento não se integra ao viver". Diante do que, uma educação moral é

[...] toda a educação que desenvolve a capacidade de participar-se eficazmente da vida social. Ela forma um caráter que não somente pratica os atos particulares socialmente necessários, como também se interessa pela contínua readaptação que é essencial ao desenvolvimento e ao progresso. $O$ interesse para aprender em todos os contatos com a vida é o interesse essencialmente moral (DEWEY, 1979a, p. 396. Grifos nosso).

É interessante notar como Dewey retira a discussão sobre a moral do viés puramente filosófico/especulativo, e traz para a sua perspectiva. Cunha e Cruz (2016) analisam essa questão e, ao apontar os seus fundamentos, afirmam que Dewey busca nos pensadores renascentistas a contribuição para superar a visão metafísica. Embora essa meta não foi plenamente alcançada na época de Dewey, acreditava que aconteceriam mudanças significativas a partir do momento em que ocorressem "[...] profundas mudanças na atitude dos homens quanto ao valor da experiência, permitindo que a moral seja comandada pela inteligência, o que trará inegáveis benefícios para toda a sociedade (CUNHA; CRUZ, 2016, p. 12).

Dewey enfatizava a inadequação dos hábitos morais e intelectuais em relação às novas condições materiais (WARDE, 1984, p. 124).

Os hábitos industriais foram os que mudaram mais rapidamente [...] enquanto as mudanças das instituições que dizem mais respeito aos moldes de pensamento e de crença só se realizaram em proporções mínimas. Este fato define a responsabilidade primária, mas de modo algum última, de um liberalismo que pretenda ser uma força vital da sociedade. A sua tarefa é, antes de tudo, a educação no sentido largo do termo. A escola é parte da obra da educação, mas, em um sentido amplo, educação inclui todas as influências que contribuem para formar atitudes e disposições (de desejo tanto quanto de crença) que constituem os hábitos dominantes da mente e do caráter (DEWEY, 1970, p. 62).

Assim, revelava a preocupação com as mudanças ocorridas em seu tempo e o descompasso com os valores necessários à essas mudanças: "O compasso da marcha foi tão rápido que se tornou praticamente impossível para as tradições e crenças subjacentes acompanharem o ritmo" (DEWEY, 1970, p. 140). Neste sentido, é possível identificar a preocupação com uma Educação Integrada para responder a esse dilema:

Nenhuma estimativa dos efeitos da cultura sobre os elementos que agora constituem liberdade será adequada, se não levar em conta as fraturas religiosas e morais que se encontram em nossa própria estrutura como pessoas. O problema da criação de genuína democracia não pode ser tratado com êxito, seja em teoria, ou na prática, se não conseguirmos transformar as presentes condições desordenadas em uma integração intelectual e moral (DEWEY, 1970, p. 140).

A educação, além disso, vincular-se-ia ao que Dewey considerava como uma outra dificuldade do capitalismo: a ausência de instituições democráticas. A educação caminharia, então, no sentido de tornar o problema consciente; condição para se marchar para a sua solução, visto que "o problema é, em parte, econômico" e também "um problema de educação" (DEWEY, 1970, p. 235). 
Dewey destacava, portanto, a importância de mudança real das instituições para a democratização da sociedade. Para tanto, seria preciso atuar não somente na reforma das instituições, mas por meio da educação "ajudar na formação de hábitos da mente e do caráter, de padrões morais e intelectuais que estejam de algum modo mais concordes com a atual marcha dos acontecimentos" (DEWEY, 1970, p. 64-65). A "educação não pode ser realizada trabalhando apenas a mente humana, sem ação que efetue mudança real nas instituições [...] O campo de batalha é também, consequentemente, aqui dentro de nós mesmos e de nossas instituições" (DEWEY, 1970, p. 65-66). Assim, o uso da inteligência em ação constituiria o principal método para resolução dos problemas e deveria "[...] guiar todas as ações públicas e, a ação política, em específico" (WARDE, 1984 p. 124).

O imperativo da educação com a função de responder aos problemas sociais, fundamenta-se na tendência filosófica do Pragmatismo, que Dewey traz para a educação:

\begin{abstract}
Qual então o verdadeiro sentido de preparação no quadro da educação? Em primeiro lugar, significa poder a pessoa, velha ou moça, extrair de sua experiência presente tudo o que nela houver para si nesse momento em que a tem. Quando a ideia de preparação se faz o objetivo dominante da atividade, as potencialidades do presente são sacrificadas a um imaginário e suposto futuro. E nessa medida, a real oportunidade de preparação para o futuro vem a se perder. $O$ ideal de usar o presente simplesmente para se preparar para 0 futuro contradiz-se a si mesmo (DEWEY, 1979b, p. 43).
\end{abstract}

A compreensão da obra de Dewey, que não leve em conta a compreensão do Pragmatismo "é limitada e parcial" (SOUZA, 2012, p. 228). William James (1842-1910) foi um dos fundadores do Pragmatismo, primeira corrente filosófica nascida nos Estados Unidos (SILVA, 2006, p. 100). Ao realizar uma biografia de Dewey, Jane Dewey afirma que "William James é de longe a maior influência individual na mudança de direção do pensamento filosófico de Dewey." (DEWEY, Jane, apudWARDE, 2013, p. 184). Willian James considera que, dependendo do ponto de vista de que se parte, pode-se estar certo ou errado. Propõe, então, um método pragmático para solucionar as intermináveis disputas metafísicas, concluindo que a função da filosofia deveria ser "prática" (experimental) e não teórica (abstrata), pois achava que as doutrinas (conceitos) têm um valor prático, utilitário (DORE SOARES, 2000, p. 246-247), mas no sentido do interesse público da sociedade.

Dessa forma, William James e George H. Mead (1863-1931), juntamente com Charles S. Pierce (1839-1914) e o próprio John Dewey são considerados os fundadores do movimento filosófico conhecido como Pragmatismo, tido como genuinamente americano cujos, princípios básicos podem ser assim resumidos: o pensamento e a ação devem formar um todo indivisível, o que implica tratar qualquer formulação teórica como hipótese ativa que carece de demonstração em situação prática de vida; as constantes transformações sociais fazem com que a realidade não constitua um sistema acabado e imutável; a inteligência garante ao homem capacidade para alterar as condições de sua própria experiência (CUNHA, 1994, p. 19).

Pode-se afirmar assim, que em Dewey, a ideia de uma Educação Integrada articula-se à sua filosofia pragmática:

[...] existe já oportunidade para dar-se uma educação que, tendo em mira, em traços mais salientes, o trabalho, reconciliará a cultura liberal com a educação socialmente útil, com a aptidão de compartir, eficientemente e com prazer, ocupações produtivas. E tal educação 
tenderá por si mesma a eliminar os males da presente situação econômica [...] Uma educação que unificasse a atitude mental dos membros da sociedade contribuiria muito para unificar a própria sociedade (Dewey, 1979a, p. 286).

A preocupação de Dewey é de acabar, sim, com o isolamento entre as classes, pois isso prejudicaria o progresso. Para fazer isso, reafirma-se o seu princípio democrático, pois a "forma de vida associada" acabaria também com as barreiras entre as classes, pois integraria os sujeitos (DEWEY, 1979a, p. 93). A escola também assumiria a tarefa de romper esse isolamento:

A convivência na escola de jovens, de diversas raças e religiões, e de costumes dessemelhantes, proporciona a todos um meio novo e mais vasto. Os estudos comuns acostumam a todos, por igual, a um descortino de horizontes mais amplos do que os visíveis a qualquer grupo, quando este se encontra isolado. [...] A escola tem igualmente a função de coordenar na vida mental de cada indivíduo, as diversas influências dos vários meios sociais em que ele vive [...] impõe à escola uma função fortalecedora e integradora [...] $\mathrm{A}$ extensão, no espaço, do número de indivíduos que participam de um mesmo interesse de tal modo que cada um tenha de pautar suas próprias ações pelas ações dos outros e de considerar as ações alheias para orientar e dirigir as suas próprias, equivale à supressão daquelas barreiras de classe, raça e território nacional que impedem que o homem perceba toda a significação e importância de sua atividade (DEWEY, 1979a, p. 23-93. Grifos nosso).

Considerando os desafios decorrentes da nova fase do liberalismo, pode-se observar como a concepção de Educação/Escola Integrada relaciona-se com a preocupação de integração social dos indivíduos na sociedade, objetivando "harmonizar" suas relações:

A crise do liberalismo, como disse no princípio, decorre do fato de a sociedade se defrontar com um novo problema [...] o da organização social [...] O surgimento de uma política nacional que pretende representar a ordem, a disciplina, e a autoridade espiritual, capaz de contrabalançar a desintegração social, é um trágico comentário do primitivo liberalismo para lidar com o novo problema, que seu próprio sucesso precipitou (DEWEY, 1970, p. 58).

Pode-se dizer, também, que a preocupação com as artes, a música, o teatro, a pintura, etc., está comprometida com as bases culturais da democracia, inclusive, como uma forma de se combater o Totalitarismo, revelando uma perspectiva de integração social e, portanto, de sua concepção de Educação Integrada.

Não se formou o hábito de incluir as artes, as belas-artes, como parte importante das condições sociais que influem nas instituições democráticas e na liberdade pessoal. Mesmo depois de se haver admitido a influência da situação da indústria e da ciência natural, ainda tendemos a recusar a ideia de que a literatura, a música, a pintura, o teatro, a arquitetura tem qualquer íntima conexão com as bases culturais da democracia [...] O estado das coisas nos países totalitários pode induzir-nos a rever essa opinião. Pois aí se prova que, não importando qual seja o caso em relação aos impulsos e forças que levam o artista criador à realização de sua obra, os trabalhos de arte, uma vez criados, constituem os mais poderosos dos meios de comunicação, pelos quais as emoções são despertadas [...] Começamos a compreender que emoções e imaginação são mais potentes em moldar o sentimento e a opinião pública de que a informação e a razão (Dewey, 1970, p. 103).

A defesa de Dewey da utilização das artes, também está vinculada à ideia de produzir o consentimento das massas ao capitalismo. Para tanto, seria preciso que a educação integrasse a escola à vida, articulasse às necessidades do novo momento do desenvolvimento capitalista. Uma educação que respondesse às necessidades da vida 
social, superando a dimensão meramente contemplativa da escola tradicional', voltada para a ideia de "reconstrução social", através da formação de novos hábitos e, consequentemente, de novas instituições.

Pode-se inferir aqui, o contraponto com aqueles que propõem a transformação das relações sociais de produção capitalistas, os socialistas, que almejavam a construção de uma sociedade futura, sob outras bases econômico-sociais. Para Dewey, no entanto, "[...] vivemos sempre no tempo em que estamos e não em um outro tempo" (DEWEY, $1979 b$, p. 44) e, dessa forma, "Não poderemos criar, com as nossas imaginações, alguma coisa que consideremos uma sociedade ideal. Nossa concepção deve basearse em sociedades que existam realmente, de modo a obtermos alguma exiquidade de nosso ideal" (Dewey, 1979a, p. 89).

É dessa forma que, para Dewey, o presente deveria ter como parâmetro os valores universais, os quais seriam fundamentais para a formação do "novo" homem, bem como de uma sociedade pautada no método da democracia. A "teoria do método de conhecer", exposta por Dewey, pautava-se na defesa de que

[...] o conhecimento em seu sentido estrito de alguma coisa possuída consiste em nossos recursos intelectuais - em todos os hábitos que tornam a nossa ação inteligente. Só aquilo que foi organizado em nossas disposições mentais, de modo a capacitar-nos a adequar o meio às nossas necessidades e a adaptar nossos objetivos e desejos à situação em que vivemos, é realmente conhecimento ou saber. O conhecimento não consiste em alguma coisa de que temos conhecimento atual, mas nas disposições de espírito que conscientemente adotamos para compreender o que atualmente sucede. O conhecimento, como ato, traz alguma coisa de nossos estados mentais à consciência com o fim de extinguir uma incerteza, concebendo a conexão entre nós e o mundo em que vivemos (DEWEY, 1979a, p.377-378).

Neste sentido, o passado não é está em segundo plano, mas relacionado aos problemas do presente, colocados pela perspectiva do autor da seguinte forma:

Rejeitando o conhecimento do passado com o fim de educação, iremos apenas dar-the maior importância como meio de educação. Quando assim procedemos, lançamos um problema novo no contexto educacional: Como poderá o jovem conhecer e familiarizar-se com o passado de modo tal que este conhecimento se constitua poderoso fator de sua apreciação e sentimento do presente vivo e palpitante? (DEWEY, 1979b, p. 11. Grifos do autor).

Para Dewey não existiria a necessidade de preparar o educando para o futuro. Se no presente a escola propiciasse experiências duradouras e saudáveis para 0 desenvolvimento da criança, esta seria capaz de lidar com qualquer futuro. Dewey acreditava que o dia de amanhã era uma construção que se iniciava no dia de hoje. Os cuidados com a vida presente das crianças, com o seu desenvolvimento e as suas necessidades atuais eram suficientes para a educação do homem do futuro. Assim, o estudo das antigas formas de organização social e suas realizações deveria ser norteado pelas dificuldades atuais e deveria ser utilizado para conduzir o movimento da realidade vivida (CUNHA, 1994, p. 47-51).

\footnotetext{
${ }^{5} \mathrm{O}$ termo escola tradicional passou a ser usado como uma forma de crítica à escola existente em fins do século XIX e como argumento para os defensores do escolanovismo. De forma geral, Dewey caracterizava a escola tradicional pelos fins da educação (preparação passiva das novas gerações); pelos métodos de instrução (transmissão de informações do professor para os alunos de forma que eles decorem e depois repitam) e pela disciplina escolar (DEWEY, 1979b, p. 04). Para Dewey "o conteúdo da escola tradicional estava divorciado da vida, seus métodos estavam ultrapassados e a estrutura escolar era elitista” (FAVORETO, 2008, p. 49).
} 
Assim, as necessidades imediatas, pelo que se pode compreender, se articulavam com o passado, mas não se subordinavam às necessidades históricas:

Se o ambiente, na escola ou fora dela, fornecer as condições que ponham adequadamente em ação as aptidões do imaturo, é certo beneficiar-se com isso o futuro, que é produto do presente. $\mathrm{O}$ erro não está propriamente em cuidar-se da preparação para as futuras necessidades e sim em tornar essa preparação a mola real do esforço presente (DEWEY, 1979a, p. 60).

É possível perceber como a Educação para Dewey vai muito além de uma função instrucional. O que é coerente com o próprio Pragmatismo a que Dewey se filiava. Para o Pragmatismo "[...] a filosofia não deve apenas evitar os dualismos: razão/experiência, ideal/real, teoria/prática, indivíduo/sociedade, mas combatê-los, já que o conhecimento se dá na continuidade da experiência e não apenas em sua fragmentação" (SOUZA, 2012, p. 230). Há em Dewey uma preocupação latente sobre a contribuição que a educação deve dar a sociedade, ou como a escola pode responder aos problemas enfrentados pela sociedade, seja no âmbito político (construção de uma efetiva democracia); social (diminuindo os efeitos da desigualdade social); ou filosófico/ideológico (reafirmação dos princípios liberais). A educação com uma filosofia de pensamento e ação integrados, deve ser integrada às necessidades da sociedade; $e$ contribuir para a integração entre indivíduos com classes, etnias e culturas diferentes. Passamos a analisar como, e para que isso se efetivasse, seria preciso uma pedagogia que apresentasse os elementos de uma Educação Integral.

\section{JOHN DEWEY E OS ELEMENTOS DE UMA EdUCAÇÃo INTEGRAL: O MÉTODO ATIVO, O ENSINO A PARTIR DE EXPERIÊNCIAS E O TRABALHO COMO ATIVIDADE OU “INTELIGÊNCIA EM AÇÃO”}

O objetivo desta seção é buscar extrair das discussões pedagógicas de Dewey os elementos de sua perspectiva de Educação Integral. Nesse sentido, apresentam-se os conceitos de sua proposta de educação a partir da relação entre ensino e experiência, educação e liberdade individual; e educação e trabalho.

A análise do pensamento de Dewey em relação à democracia e educação articula-se ao conceito de experiência ${ }^{6}$ e contribui para compreender o significado de Educação Integral. O conceito de experiência é elemento-chave da concepção educacional de Dewey (WARDE, 1984, p. 128). De acordo com o autor americano "[...] demonstra-se ser unicamente possível o desenvolvimento efetivo e integral do pensamento quando se recorre ao método experimental" (DEWEY, 1959, p. 107).

Para Dewey a educação é a experiência inteligente, devendo ocorrer em todas as situações, e a escola seria uma delas (WARDE, 1984, p. 128). Neste sentido, "[...] desde que os fins do liberalismo são a liberdade e a oportunidade dos indivíduos para a plena realização de suas potencialidades, toda intensidade emocional própria a esses objetivos transporta-se às ideias e atos necessários a sua efetivação" (DEWEY, 1970, p. 57).

Para Dewey, a escola deveria superar a formação decorrente da Escola Tradicional, fundamentada na imposição, aos alunos, de tradições e valores historicamente acumulados, para trabalhar o ensino a partir da experiência, visando suscitar a curiosidade, a iniciativa e os desejos particulares dos indivíduos (DEWEY, 1979b, p. 29).

\footnotetext{
${ }^{6}$ Sobre as implicações filosóficas envolvidas no conceito de experiência, ver, por exemplo, "Dewey: a filosofia especulativa da experiência", capítulo da tese de doutorado de Sabina Silva (2010).
} 
Dewey apontava que seria preciso que dada experiência conduzisse a campo não previamente conhecido, caso contrário, não surgiriam problemas e sem eles não haveriam estímulos para pensar. Distinguia, assim, a educação baseada em experiência da educação tradicional, pelo fato de que as condições encontradas na experiência atual do aluno eram utilizadas como fontes de problemas, ao passo que na Escola Tradicional a fonte dos problemas estaria fora da experiência do aluno (CUNHA, 1994, p. 80).

A vinculação entre a educação e a vida, relaciona-se com a ampliação do conceito de conteúdo escolar, sobretudo na direção de considerar as atitudes e os hábitos ${ }^{7}$. Expressa, também, a estreita vinculação entre educação/escola/sociedade; evidenciando, ao mesmo tempo, as preocupações de uma Educação Integrada e a concepção de uma Educação Integral:

[...] define-se educação como a aquisição dos hábitos indispensáveis à adaptação do indivíduo a seu ambiente. Esta definição se aplica a um aspecto fundamental do crescimento. Mas é essencial que se entenda tal ajustamento ou adaptação no sentido ativo de assenhoramento de meios para a realização de fins em vista. [...] Os hábitos dão-nos o domínio sobre o meio e a capacidade de utilizá-lo para fins humanos [...] Os hábitos ativos subentendem reflexão, invenção e iniciativa para dirigir as aptidões a novos fins. Eles são o contrário da rotina, que assinala uma parada no desenvolvimento. Uma vez que este é a característica da vida, educação e desenvolvimento constituem uma coisa só (Dewey, 1979a, p. 50-56-57).

A justificativa de Dewey em relação à crítica à Escola Tradicional é porque ela negaria um dos princípios básicos do liberalismo: a liberdade:

O esquema tradicional é, em essência, esquema de imposição de cima para baixo e de fora para dentro. Impõe padrões, matérias de estudo e métodos de adultos sobre os que estão ainda crescendo lentamente para a maturidade (DEWEY, 1979b, p. 5).

Contrapondo a isso, propõe os chamados "métodos ativos" com uma maior participação dos alunos na escolha sobre o que estudar; evidenciando, dessa forma, os princípios da liberdade e do esforço individual. Neste sentido, para Dewey as aprendizagens "colaterais", como as de formação de atitudes permanentes de gosto e desgosto, podem ser, muitas vezes, mais importantes do que a lição de ortografia, de geografia ou de história. Essas são as atitudes com as quais irão contar fundamentalmente no futuro. A mais importante atitude a ser formada é a do desejo de continuar a aprender8 (DEWEY, 1979b, p. 42).

Nesta dimensão, o rigor e a disciplina da Escola Tradicional foram igualmente combatidos por Dewey, visto que dificultariam o desenvolvimento tanto da liberdade, quanto da individualidade.

\footnotetext{
${ }^{7}$ Essa é umas das características da obra de Dewey que está fortemente presente nas Pedagogias contemporâneas. Para uma análise sobre outros elementos "herdados" da Pedagogia de John Dewey, ver dentre outros: BORGES. L. P. F. Democracia e educação: uma análise crítica às políticas educacionais no Brasil (1995-2002). Tese de Doutorado. Universidade Federal de São Carlos. São Carlos, 2006.; DUARTE, Newton. Vigotski e o "aprender a aprender": crítica às apropriações neoliberais e pós-modernas à teoria vigotskiana. 4. ed. Campinas: Autores Associados, 2006; SHIROMA, E. O; CAMPOS, R. F. O resgate da Escola Nova pelas reformas educacionais contemporâneas. Revista Brasileira de Estudos Pedagógicos. Brasília. Vol. 80, n. 196. Set/dez 1999.

${ }^{8}$ Neste debate é possível identificar como as ideias de Dewey "ecoaram" nas reformas educacionais da década de 1990 no Brasil, conforme apontam Souza e Martineli (2009). Destaca-se neste ponto, a similaridade com a Pedagogia das Competências, ou do "aprender a aprender", sintetizadas por Newton Duarte (2001) em quatro posicionamentos: 1) aquilo que o indivíduo aprende por si mesmo é superior àquilo que lhe é transmitido por outra pessoa; 2) o método de construção do conhecimento é mais importante do que o conhecimento já produzido socialmente; 3 ) a atividade do aluno deve ser impulsionada pelos seus interesses e necessidades; 4) a educação deve preparar os indivíduos para um mundo em acelerado processo de mudança, instrumentalizando-os para competirem por postos de trabalho, cada vez mais escassos.
} 
À imposição de cima para baixo, opõe-se a expressão e cultivo da individualidade; à disciplina externa, opõe-se a atividade livre; a aprender por livros e professores, aprender por experiência; à aquisição por exercício e treino de habilidades e técnicas isoladas, a sua aquisição como meios para atingir fins que respondem a apelos diretos e vitais do aluno; à preparação para um futuro mais ou menos remoto opõe-se aproveitar ao máximo das oportunidades do presente; a fins e conhecimentos estáticos opõe-se a tomada de contacto com um mundo em mudança (DEWEY, 1979b, p. 06-07).

Segundo o autor, é necessário determinado controle dos indivíduos, mas sem a violação da liberdade para o desenvolvimento das experiências educacionais.

[...] Na escola bem organizada, o controle do indivíduo repousa dominantemente nas atividades em curso e nas situações criadas para que elas transcorram normal e frutuosamente. O professor reduz ao mínimo as ocasiões que tenha que exercer autoridade pessoal. Quando se faz necessário falar e agir firmemente, fá-lo no interesse do grupo e não como exibição de poder pessoal [...] Quando a educação se funda na experiência e a experiência educativa é concebida como um processo social, a situação muda radicalmente. O professor perde a posição de chefe ou ditador, acima e fora do grupo, para se fazer o líder das atividades do grupo (DEWEY, 1979b, p. 49-55).

Nesse processo, o planejamento também era considerado importante, devendo ser flexível para oportunizar o livre exercício da experiência individual, proporcionando condições para uma Educação Integral.

[...] cabe ao educador o dever de instituir o tipo de planejamento mais inteligente e, consequentemente, muito mais difícil. Deve ele estudar as capacidades e necessidades do grupo que tiver de educar e, ao mesmo tempo, dispor e ordenar as condições para que a matéria ou conteúdo das experiências seja tal que satisfaça aquelas necessidades e desenvolva aquelas capacidades. O planejamento deve ser suficientemente flexível para permitir o livre exercício da experiência individual e, ainda assim, suficientemente firme para dar direção ao contínuo desenvolvimento da capacidade do aluno (DEWEY, 1979b, p. 54).

Para Dewey, "à proporção que a sociedade se torna democrática, deveria orientar-se para a utilização daquelas qualidades peculiares e variáveis do indivíduo e não para a sua estratificação em classes" (CUNHA, 1979, p. 46). Dessa forma, a preocupação com a construção de um ambiente pedagógico democrático, com vistas a transpô-lo para a sociedade, articula-se, assim, com o ideal de democracia concebido para além da forma de governo, conforme já mencionado.

É indubitável que uma sociedade para a qual seria fatal a estratificação em classes separadas, deve procurar fazer que as oportunidades intelectuais sejam acessíveis a todos os indivíduos, com iguais facilidades para os mesmos [...]. Uma sociedade móvel, cheia de canais distribuidores de todas as mudanças ocorridas em qualquer parte, deve tratar de fazer que seus membros sejam educados de modo a possuírem iniciativa individual e adaptabilidade. Se não fizerem assim, eles serão esmagados pelas mudanças em que se virem envolvidos e cujas associações ou significações eles não percebem (DEWEY, 1979a, p. 93-94).

Além do objetivo de desenvolver as aptidões individuais, existia a preocupação com o desenvolvimento tecnológico do capitalismo e o acompanhamento da escola nesse processo: A adesão ao método de ensino a partir das experiências, "[...] não só constitui a via mais direta para compreensão da própria Ciência, como é também o mais seguro caminho para compreensão dos problemas industriais da sociedade presente" (DEWEY, 1979b, p. 82).

Nessa perspectiva, o trabalho aparece como um elemento importante, na perspectiva de 
uma Educação Integral. A escola deveria oportunizar o contato com experiências que possibilitariam, inclusive, a integração com o trabalho. Dewey destacava que "A única preparação adequada para as ocupações é feita por meio de ocupações" (DEWEY, 1979a, p. 342). Salientava, ainda, que a escola não deveria ser um prolongamento da empresa, mas era necessário "[...] utilizar os fatores da indústria para tornar a vida escolar mais ativa, mais cheia de significações imediatas, mais associadas à experiência extraescolar" (DEWEY, 1979a, p. 348).

Dewey concebia a escola em correlação com a Revolução Industrial, que mudou essencialmente o trabalho (FAVORETO, 2008, p. 52). Segundo Dewey, a indústria já não era mais doméstica e local e, sim, mundial. Deixou de ser um processo empírico, rotineiro, estabelecido pelo costume, e passou a se fundamentar na tecnologia ou maquinarias resultantes de descobertas matemáticas, físicas, químicas, etc. As ocupações industriais, por sua vez, têm um conteúdo intelectual e possibilidades culturais infinitamente maiores (DEWEY, 1979a, p. 346-347).

Assim, a escola deveria ter a preocupação de exercer a capacidade de readaptação do indivíduo às condições de vida e de desenvolvê-lo nos aspectos intelectuais (CUNHA, 1979, p. 48). Tendo essa preocupação, a escola provocaria duas repercussões: "exercitaria a capacidade de readaptação às mudanças de condições, de modo que o futuro trabalhador não se tornasse cegamente submisso ao destino que the fosse imposto", e também faria com que os "representantes da classe social mais privilegiada", aumentassem a "sua simpatia pelo trabalho", criando "uma disposição mental" favorável a "descobrir elementos culturais em uma atividade útil e aumentar o senso dos seus deveres sociais" (DEWEY, 1979a, p. 352-353).

Evidencia-se aqui, a aproximação com a preocupação socialista em relação ao trabalho, marca do movimento Escolanovista e que, em Dewey, parte da seguinte inquietação: "Torna-se imperativa a necessidade de uma educação que familiarize os operários com os fundamentos e alcance científicos e sociais de sua atividade, porque os que não a tiverem recebido degradar-se-ão inevitavelmente ao papel de apêndices das máquinas que trabalham" (DEWEY, 1979a, p. 347).

Dewey, no entanto, apontava que a escola era quem poderia evitar essa degradação da mente do trabalhador, causada pelo trabalho mecânico. A escola alcançaria esse objetivo a partir do momento em que todos utilizassem os benefícios que a ciência industrial disponibilizou à humanidade (FAVORETO, 2008, p. 52-53). Para Dewey, a construção dessa escola seria tarefa difícil, destacando, portanto, as principais resistências:

Este ideal precisaria batalhar não só contra a inércia das presentes tradições educacionais, como também contra a hostilidade daqueles que se entrincheiram no domínio da aparelhagem industrial e que entendem que, caso se tornasse geral semelhante sistema educativo, ele constituiria uma ameaça à sua faculdade de utilizar dos outros indivíduos para a realização dos seus próprios fins (DEWEY, 1979a, p. 352).

Os vínculos entre a escola e o trabalho são constatados com grande evidência no final do século XIX, nos Estados Unidos. Em 1876, ocorreu um evento, na Filadélfia, para discutir a influência da ciência nos progressos da indústria e as inovações pedagógicas que estavam mais diretamente associadas à prosperidade industrial. Destaque para a participação do russo Victor Della Vos, diretor da "Escola Técnica Imperial de Moscou", fundada em 1868, o qual teria aplicado um método de ensino, que complementaria o trabalho da matemática, da física e da engenharia, com o treinamento no trabalho 
(DORE SOARES, 2000, p. 240).

Ao se preocupar com o trabalho, Dewey também o tomou a partir do princípio de atividade; expressão da "inteligência em ação": "Tudo, afinal, se resume na atividade em que entra a inteligência reagindo ao que lhe é externamente apresentado" (DEWEY, 1930, p. 72 apud DORE SOARES, 2000, p. 256).

O trabalho, na perspectiva de Dewey seria, inclusive, uma forma de responder ao dilema do início do século XX, no âmbito da ciência, da distinção entre o sujeito e o objeto. Não existiria melhor forma para mediar a relação entre sujeito e objeto do que o trabalho (DEWEY, 1930, p. 106 apud DORE SOARES, 2000, p. 255).

Dewey reconheceu a existência, na sociedade, de uma divisão permanente entre pessoas capazes de "viver a vida da razão" e outras capazes apenas de ter "apetites e de trabalhar"; uma divisão expressa já na Antiguidade Grega, onde a vida humana, em sua plenitude, era privilégio de poucos, à custa dos resultados do trabalho de uma maioria. Essa divisão resultou em um sistema de educação dualista: para o primeiro grupo de pessoas, uma educação que servia para uma vida autossuficiente de lazeres, dedicados ao saber pelo saber (característica da Escola Erudita, Tradicional); para o segundo grupo de pessoas, uma educação para a preparação utilitária e prática, voltada para as ocupações, desprovida de conteúdo intelectual ou estético. Uma separação entre "a íntima atividade mental e a ação física externa" (DEWEY, 1979a, p. 286). Diante disso, a proposta de uma Educação Integral em Dewey também contemplaria a integração desses dois aspectos: a "cultura e a utilidade", sendo que "O problema da educação em uma sociedade democrática é acabar com esse dualismo e organizar um curso de estudos que torne a reflexão, para todos, um guia no livre exercício da atividade prática" (DEWEY, 1979a, p. 286-287).

Se a divisão entre aqueles que trabalhavam e aqueles que viviam plenamente havia resultado numa educação dualista, a tarefa da educação seria de realizar o inverso, contribuindo, portanto, com a unificação da própria sociedade: "Uma educação que unificasse a atitude mental dos membros da sociedade contribuiria muito para unificar a própria sociedade" (DEWEY, 1979a, p. 286). Evidencia-se mais uma vez, como a concepção de Educação Integral está vinculada à Educação Integrada.

Dewey criticava, portanto, não somente o ensino destinado aos trabalhadores, mas, também, o ensino das elites. A unificação da educação de ambos os segmentos sociais se daria a partir do ensino que incorporasse o trabalho como atividade, que seria distinto do trabalho econômico e do trabalho como algo "árduo" e "fastidioso". O trabalho como atividade "é alguma cousa de valor, como meio de troca, ou melhor, é, hoje, a forma de trabalho que é pago e cujo dinheiro nos habilita a adquirir outras cousas de valor mais direto". Já no sentido econômico, "é uma tarefa, uma obrigação, que envolve desusado esforço. Fazemo-lo, geralmente, sob a coação de uma necessidade estranha à natureza do labor" (DEWEY, 1930, p. 128-129 apud DORE SOARES, 2000, p. 255-256). O trabalho manual ou industrial apresentava pouca coisa em que se empreguem os sentimentos ou a imaginação e "são séries de aturados esforços mais ou menos maquinais" (DEWEY, 1979a, p. 225). Não seria esse o trabalho que deveria ser adotado pela escola. Dewey não contestava a existência do trabalho na indústria, como produto da divisão de classes, nem tampouco defendia a sua abolição; apenas apontou que a escola deveria ter outro princípio de trabalho.

O trabalho deveria ser tomado no sentido de uma "ação inteligente", não poderia ser julgado pelo valor do produto que cria e sim do ponto de vista da "invenção, do engenho, 
da observação". O trabalho, portanto, significava, "Todas as formas de expressão e de construção com instrumentos e materiais, todas as formas de atividade manual e artística (DEWEY, 1930, p. 131 apud DORE SOARES, 2000, p. 256).

Se a educação se daria a partir da experiência, a escola deveria oferecer a maior diversidade possível das mesmas para serem exploradas pelos alunos; condição que fundamenta, de certo modo, a concepção de uma Educação Integrada e Integral, bem como a concepção de trabalho em Dewey.

\begin{abstract}
Excursões, jardinagem, cozinhar, costurar, imprimir, encadernar livros, tecer, pintar, desenhar, cantar, dramatizar, contar histórias, ler e escrever - como trabalhos ativos e com finalidades sociais (e não como simples exercícios para adquirir proficiência que futuramente seja usada) além de uma inumerável variedade de brinquedos e jogos, constituem algumas espécies de ocupação. [...] O problema do educador é fazer que os alunos se dediquem de tal modo a essas atividades que, ao mesmo tempo em que adquiram habilidade manual e eficiência técnica e encontrem satisfação imediata nesses atos, e juntamente se preparem para a habilitação ulterior, sejam essas atividades subordinadas à educação - isto é, à obtenção de resultados intelectuais e à formação de tendências sociáveis (DEWEY, 1979a, p. 216-217).
\end{abstract}

A utilização de trabalhos manuais na escola seria um meio importante de dirigir a educação ao abstrato, despertando o interesse pelas questões intelectuais envolvidas no trabalho (DORE SOARES, 2000, p. 256). Atividades como carpintaria, por exemplo, deveria despertar o empenho para resolver os problemas de geometria e mecânica. $O$ trabalho na cozinha da escola, por sua vez, caminharia para a experimentação química, para a fisiologia, a higiene e o crescimento corporal (DORE SOARES, 2000, p. 257). Percebe-se, assim, que o trabalho na perspectiva de Dewey assume várias dimensões, partindo de sua preocupação social, para a sua Pedagogia e chegando à proposição da reorganização da escola.

\title{
CONSIDERAÇÕES FINAIS
}

Os elementos apresentados sobre as concepções de Educação Integral e Integrada em Dewey, permitem algumas considerações a partir da relação entre os conceitos que nos propomos a problematizar neste artigo. Pode-se se dizer que a relação entre os conceitos de educação e contradições sociais; educação e democracia; educação moral e formação de hábitos morais e intelectuais, se aproximam mais da concepção de Educação Integrada. Por sua vez, a relação entre os conceitos de ensino e experiência; educação e liberdade individual; e educação e trabalho expressam os elementos de uma Educação Integral.

Sobre a relação educação e contradições sociais, as elaborações de Dewey vinculamse as preocupações enfrentadas pelo Liberalismo, desde os fins do século XIX e início do século $X X$. Os problemas causados pela divisão de classes, a pobreza, 0 desemprego, etc., são atribuídos pelo Liberalismo à falta de igualdade de direitos e de oportunidades, na sociedade, para que todos, através de sua competência e esforço, pudessem vencer. Assim, a escola passou a assumir, a partir do início do século XX, com maior intensidade, a ideia de que proporcionaria essa igualdade de competição e, para isso, precisaria estar articulada com os ideais liberais; tarefa esta que o movimento Escolanovista assumiu. O reconhecimento de Dewey dos problemas do capitalismo indica a concepção de uma educação não apenas vinculada à instrução, mas de uma proposta de Educação Integrada à sociedade, ou seja, era preciso vincular a tarefa 
educativa aos problemas imediatos do capitalismo.

Sobre a relação entre educação e democracia, a ausência da Democracia foi considerada como uma das causas dos problemas da época. Ao reformar as instituições, Dewey acreditava que se estaria "revolucionando" a sociedade. O entendimento de Dewey sobre o que era Democracia, conceito que extrapola o âmbito da ação política parlamentar, ao considerá-la como uma forma de vida associada, estava centrada na tese de que "educação é vida" e, portanto, caberia à escola reproduzir o tipo de sociedade que almejasse construir, a partir de uma educação pautada nos valores democráticos liberais colocados, por esse autor, como valores universais. Essa ideia está vinculada a relação entre educação moral e formação de hábitos morais e intelectuais, pois em Dewey a preocupação era a de que a nova escola vinculasse os métodos de conhecimento com o desenvolvimento da nova moral, necessária à sociedade industrial capitalista, pautada nos princípios liberais.

Neste sentido, a perspectiva de uma Educação Integrada, em Dewey, estava relacionada a formação do "novo" homem a partir das artes, da música, do teatro, dos valores universais do Liberalismo, tendo como referência os problemas da vida, ou seja, era preciso enfrentar a "desintegração social". A escola proposta por Dewey, ao se integrar a sociedade, integraria, também, os indivíduos "excluídos". Assim, "à medida que a escola passaria a produzir indivíduos diferentes, estaria contribuindo para a mudança na sociedade" (CUNHA, 1979, p. 47). Isso, de certa forma, expressava uma das questões centrais em relação a sua crítica à Escola Tradicional: de que ela estava desintegrada da vida, com seus métodos ultrapassados e sua estrutura elitista, conforme mencionado.

Vinculados a preocupação da integração da escola com sociedade, mediados pelos valores liberais, Dewey defendia a mudança no modelo de formação da Escola Tradicional e propõe o ensino a partir da experiência, o que pressupõe uma Educação Integral do sujeito/aluno. Esta é outra dimensão do já conhecido preceito deweyano "educação é vida", que coloca as experiências do aluno como fonte de aprendizagem. Os novos hábitos necessários, citados acima, se desenvolveriam na perspectiva da vivência, experimentação individual ou de envolvimento ativo do aluno na educação.

Isso leva à outra preocupação de Dewey, a relação entre educação e liberdade individual. O ensino a partir da experiência pressupõe a liberdade do aluno, entendida, tanto como valor a ser defendido, quanto como prática a ser exercida no interior das atividades escolares. Revela uma das dimensões de sua proposta de Educação Integral, onde o aluno deixa de ser apenas sujeito em preparação pela via do conhecimento, mas sujeito pleno, exercitando sua "liberdade" enquanto aprende.

A discussão da relação entre educação e trabalho se apresenta como a mais reveladora da concepção de Educação Integral em Dewey, ao mesmo tempo em que vincula vários conceitos da concepção pedagógica desse autor. O trabalho incorporado pela escola, na dimensão do ensino a partir da experiência, revelaria a inteligência em ação, a integração da escola com a sociedade e a realização dos preceitos liberais. Dewey via no trabalho da sociedade industrial um conteúdo intelectual e possibilidades culturais, não na perspectiva de tornar as escolas "apêndices da indústria" como já apontava a crítica socialista à escola, mas para tornar a vida escolar mais ativa, mais associada à experiência extraescolar.

A perspectiva da relação entre educação e trabalho em Dewey também expressa a concepção de Educação Integral porque reconhece a existência na sociedade de uma 
divisão entre aqueles que "pensam" e aqueles que "trabalham". Essa separação teria dado origem ao dualismo na educação, onde uma minoria tem uma educação que serve a uma vida autossuficiente de lazeres dedicados ao saber pelo saber, enquanto a maioria tem uma educação voltada para a preparação prática para as ocupações mecânicas, desprovida de conteúdo intelectual e estético (DEWEY, 1979a, p. 286). Porém, para inverter essa situação, Dewey defende, numa perspectiva integral, que uma educação unificada, unificaria a sociedade (DEWEY, 1979a, p. 286).

É nessa perspectiva que Dewey passa a defender a utilização de trabalhos manuais na escola, o que também revela a sua concepção de Educação Integral. Primeiro porque pela própria definição envolve a educação com uma dimensão além do intelecto, mas a vinculação deste com o corpo. Segundo porque a presença dos trabalhos manuais possibilitaria vínculos com os conhecimentos de geometria, química, higiene, entre outros, conforme apontado.

Enfim, é possível afirmar que em John Dewey, a proposta de Educação Integrada é indissociável da proposta de Educação Integral. A necessidade de que a escola desempenhasse uma função mais ampla - reconhecendo e enfrentando os problemas gerados pelo capitalismo - tornava imperativo uma educação diferente, integral, que formasse 0 indivíduo em todas as dimensões necessárias para a sociedade liberal, principalmente comprometido como os ideais da Democracia.

\section{REFERÊNCIAS}

ARANHA, Lúcia de Arruda. História da educação e da pedagogia. 3. ed. São Paulo: Moderna, 2006.

ARISTÓTELES. Política. Disponível em: http://www.dominiopublico.gov.br/download/texto-/bk000426.pdf. Acesso em: 23 set. 2008.

BORGES, Lílian Faria Porto. Democracia e educação: uma análise crítica às políticas educacionais no Brasil (1995-2002). Tese de Doutorado, Universidade Federal de São Carlos, São Carlos, 2006.

CAVALIERE, Ana Maria Villela. Quantidade e Racionalidade do Tempo de Escola: Debates no Brasil e no Mundo. TEIAS - Revista da Faculdade de Educação/UERJ - no 6 dezembro, 2002.

CUNHA, Luis Antonio. Educação e desenvolvimento social no Brasil. Rio de Janeiro: F. Alves, 1979.

CUNHA, Marcus Vinicius da. John Dewey e o pensamento educacional brasileiro: a centralidade da noção de movimento. Revista Brasileira de Educação. Rio de Janeiro, n. 17, p. 86-99, Ago. 2001. Disponível em: https://doi.org/10.1590/S1413-24782001000200007. Acesso em: 13 mai. 2020.

CUNHA, Marcus Vinicius da. Uma filosofia para educadores na sala de aula. Petrópolis: Vozes, 1994.

CUNHA, Marcus Vinicius da; CRUZ, Paulo Fernando Aleixo da. A história da filosofia no discurso de John Dewey sobre a moral. Perspectiva. Florianópolis, v. 34, n. 1, jan./abr. 2016 Disponível em: https://periodicos.ufsc.br/index.php/perspectiva/article/view/2175-795X.2016v34n1p286-/31944 Acesso em: 02 fev. 2017.

DEWEY, John. Como pensamos. São Paulo: Companhia Editora Nacional, 1959.

DEWEY, John. Liberalismo, Liberdade e Cultura. São Paulo: Companhia Editora Nacional. Editora da Universidade de São Paulo, 1970.

DEWEY, John. Democracia e educação. 4. ed. São Paulo: Editora Nacional. 1979a.

DEWEY, John. Experiência e educação. 3. ed. São Paulo: Editora Nacional, 1979b.

DORE SOARES, Rosemary. A concepção gramsciana do Estado e o debate sobre a escola. ljuí: Editora UNIJUÍ, 2000.

DUARTE, Newton. As pedagogias do "aprender a aprender" e algumas ilusões da assim chamada sociedade do conhecimento. Revista Brasileira de Educação. Rio de Janeiro, n. 18, dez. 2001. Disponível 
em: http://dx.doi.org/10.1590/S1413-24782001000300004. Acesso em 13 mai. 2020.

FAVORETO, Aparecida. Marxismo e educação no Brasil (1922-1935): o discurso do PCB e de seus intelectuais. Curitiba, Tese de Doutorado. Universidade Federal do Paraná, 2008.

FREITAS, Cezar Ricardo de. O Escolanovismo e a Pedagogia Socialista na União Soviética no início do século XX e as concepções de Educação Integral e Integrada. Cascavel, Dissertação de Mestrado. Universidade Estadual do Oeste do Paraná - UNIOESTE, 2009.

JONES, Elizabeth. E por falar em John Dewey... Perspectiva, Florianópolis, v. 7, n. 13, jan. 1989. Disponível em: https://periodicos.ufsc.br/index.php/perspectiva/article/view/9020/8400. Acesso em: 02 fev. 2017.

LARROYO, Francisco. História geral da pedagogia. São Paulo: Mestre Jou, 1982.

PEIXOTO, Madalena Guasco. A condição política na pós-modernidade: a questão da democracia. São Paulo: EDUC, 1998.

SAVIANI, Dermeval. Escola e Democracia: teorias da educação, curvatura da vara, onze teses sobre educação e política. São Paulo: Cortez,1989.

SILVA, Felipe Carreira. Habermas, Rorty e o Pragmatismo Americano. DADOS - Revista de Ciências Sociais, Rio de Janeiro, v. 49, n. 1, 2006. Disponível em: http://www.scielo.br/scielo.php?script=sci_arttext\&pid=S0011-52582006000100005\&lng=en\&nrm=iso Acesso em: 18 mai. 2017.

SILVA, Sabina Maura. Matrizes filosóficas do pensamento de Anísio Teixeira. Belo Horizonte, Tese de Doutorado. Universidade Federal de Minas Gerais, 2010.

SOUZA, Rodrigo Augusto de. Os Fundamentos da Pedagogia de John Dewey: uma reflexão sobre a epistemologia pragmatista. Revista Contrapontos - Eletrônica, v. 12 - n. 2.mai-ago. 2012. Disponível em: http://siaiap32.univali.br/seer/index.php/rc/article/view/2087/2247 Acesso em: 02 fev. 2017.

SOUZA, Rodrigo A.; MARTINELLI, Telma A. Considerações históricas sobre a influência de John Dewey no pensamento pedagógico brasileiro. Revista HISTEDBR On-line, Campinas, n. 35, p. 160-162, set.2009. Disponível em: https://doi.org/10.20396/rho.v9i35.8639620. Acesso em: 13 mai. 2020.

WARDE, Mirian Jorge. Liberalismo e Educação. Tese (Doutorado). PUC, São Paulo, 1984.

WARDE, Mirian Jorge. Notas sobre as fontes de formação de John Dewey com base no próprio autor. Educar em Revista. abr./jun., n. 48, 2013. Disponível em http://www.scielo.br/pdf/er/n48/n48a11.pdf Acesso em: 03 abr. 2016.

Data da submissão: $14 / 04 / 2020$

Data da aprovação: 19/08/2020 